\title{
Construction and Prospect of Community Convenience System
}

\author{
Yajie Liao ${ }^{1, a^{*}}$, Gongfa $\mathrm{Li}^{1, b}$ and Wenlong $\mathrm{Hu}^{1, \mathrm{c}}$ \\ ${ }^{1}$ Wuhan University of Science and Technology, China \\ a869216247@qq.com, bligongfa@wust.edu.cn, '942599328@qq.com,
}

\begin{abstract}
Keywords: Community convenience service; Convenience system; Future community; Services Optimization
\end{abstract}

\begin{abstract}
In this paper, in order to better construct the community convenience system, we started from the definition of community convenient system and the current situation and detailed the functions which the modern community convenience systems should provide in constructing, such as convenient services, information dissemination, community management and life information as well as their implementation practical methods. This paper also discussed the further development of community convenience system, showed an advanced and systematized modern community service system, which greatly optimized daily life of community residents.
\end{abstract}

\section{Introduction}

Community is the element of a city, with the core resources of social primary organization. The role communities played in the process of constructing Harmonious Socialist Society is gradually getting more important. Along with the gradually increased of annual social urbanization rate, the difficulty of managing the flowing people in community is increasing, so how to manage a community scientifically and efficiently using modern information technology become a major subject in Harmonious Socialist Society constructing, and the community convenient system emerged responding to the call our time. After intensively analysis into the current situation of communities, we proposed an integrated management according to the shortages in current community systems, which concluded in following four aspects: Convenience Services, Information Dissemination, Community Management and Life Information. We should focus on integrating of community service resources in small range and solving the problems of community service in handle daily life trouble etc. surrounding the requirements of resident's daily life and on the condition of the trust between supply and requisitioning parties to provide free door-to-door service, in turn to achieve the improvement of services efficiency. By understanding the lifestyle and consumption preference of the residents to provide the best service for them.

\section{A Summary of Community Convenience System}

Community Convenient Service and Community Public Service. Community service has become a high-frequency words, it has widely market space, but the related concepts of cognition was little of accurate, ordinary community residents' concrete concept of "public service" and "convenience services" comparatively fuzzy. "Public service" mainly indicates welfare service of whole society [1], and the simple explanation on the "convenience services" is "Encourage and support all kinds of organizations, enterprises and individuals to carry out community service business. Encourage the relevant enterprises to provide shopping, catering, housekeeping, laundry, maintenance, recycling of renewable resources, intermediary and other community services." the related content of "community convenience service" was more dispersion, and it did not make a clear definition and systematic planning.

Current Situation of Community Convenience Service. Community service through 30 years of development from the beginning of reform and opening to now has been made great progress [2]. Community service network system of city has been formed based on community convenience service institutions [3]. Service supply trend is also gradually showing of diversified [4]. Devoted to wildly used computer network technology in community convenience service system, establishing 
information network platform, to provide informational service of more efficient and convenient for community residents.

Problems Existing of Community Convenience Service. 1) Cognition of community convenience services was not sufficient, lack of awareness of service, convenience services is major reflected in government behavior [5], Residents' willingness to participate is not strong [6]; 2) Resource of community convenience service system integration is not enough, all kinds of relative independent community organizations do not have unified planning, the resources of services of community can be provided are more scattered; 3) The modern way of life lend to lack of communication between the staff of community and community residents. The staff of community can not get fully trusted in psychologically, and also very difficult to start the future work.

\section{Construction of Community Convenience System}

Because of there was not unveil the detailed rules of appropriate measures of timely after the national correlation department to formulate corresponding policies and regulations, it lack of maneuverability [7], so the community convenience service system of this paper constructed is the supplement and refinement for community public service system in some extent, and which were integrated into four small direction finally: Convenience Services, Information Dissemination, Community Management, Life Information.

Function of Convenience Service. Based on community residents' variety for the demand forms of community convenience system, the most important realization forms of community convenience system was the function of convenience service. Convenience services should include certain the participation of the masses, let the residents involved in the convenience service naturally. The concrete implementation direction of convenience services as shown in Fig. 1.

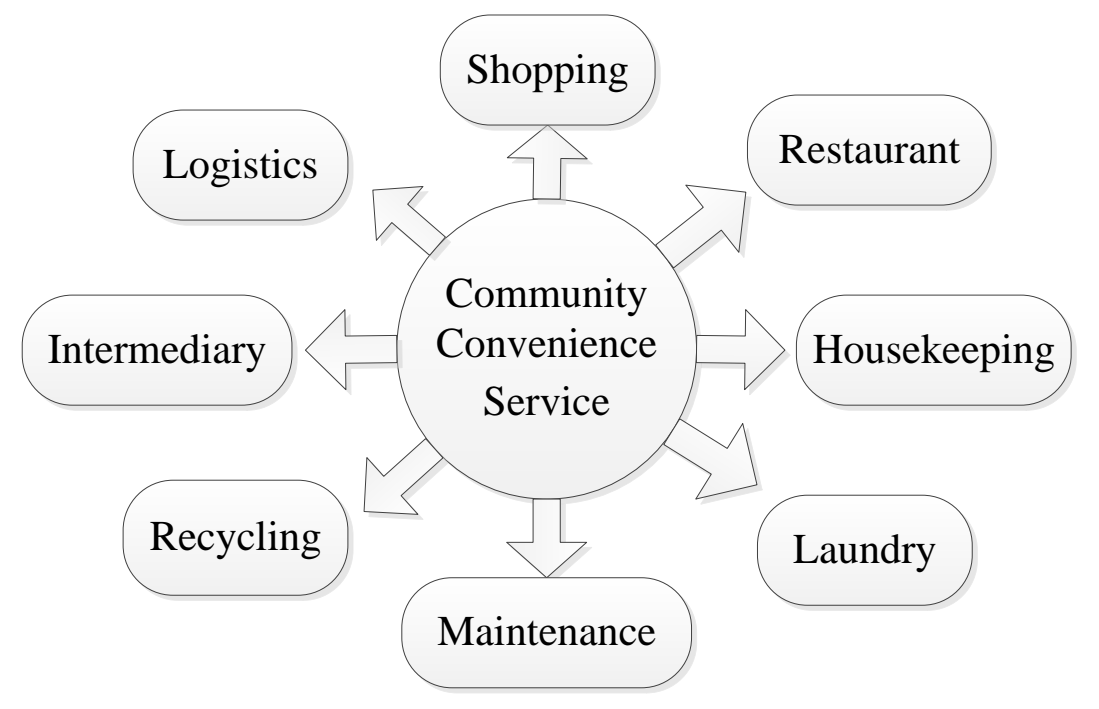

Figure 1. Function of Community Convenience Service

1) Functions of community convenience embodiment in shopping and restaurant. Community, after unified the resources of internal consumption, with the business that be willing to cuts prices to cooperation in the establishment of community convenience station. Mainly engaged in vegetables and grain and other daily food supplies, and the price of the commodity below the average prices of market. To retain existing community supermarket operators or job seekers or other low-income people as stationmaster of community convenience station to storage and sale the goods. Construct method for convenience station and service characteristics as shown in Fig. 2. 


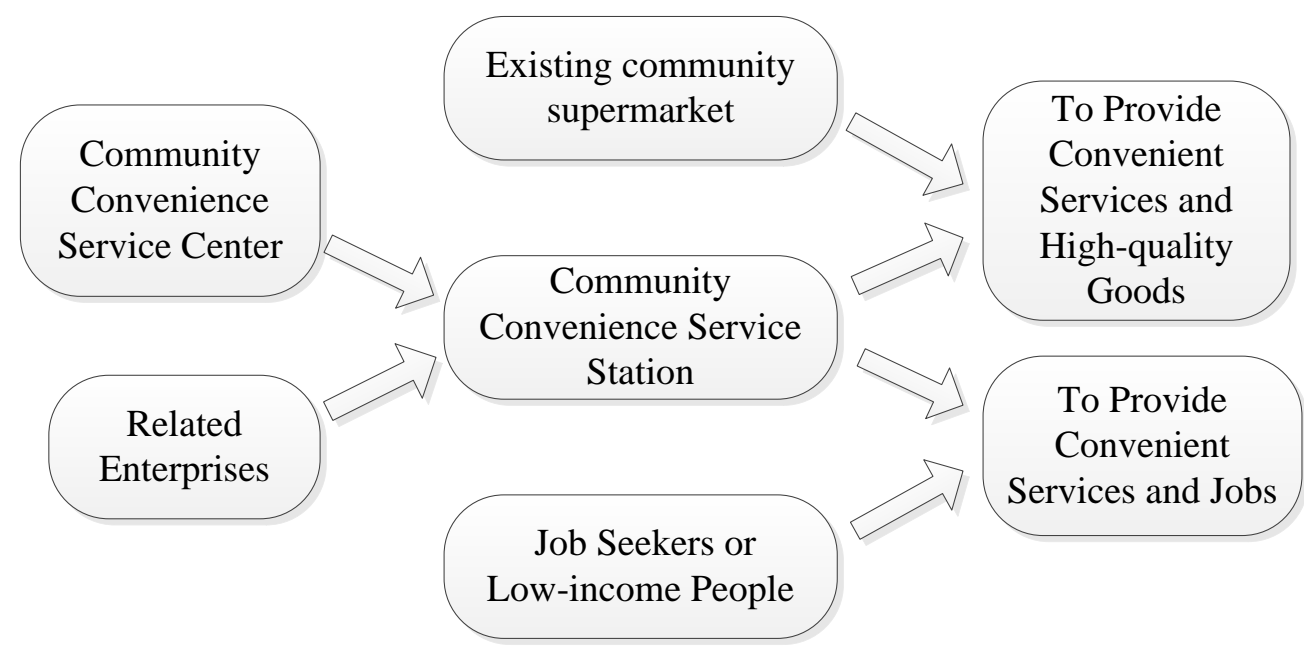

Figure 2. Construct Method for Convenience Station and Service Characteristics

2) Functions of community convenience embodiment in Housekeeping, laundry, maintenance and recycling. The community service center with the community as the center, with the distance of fifteen minute walk as the radius statistics existing resources of convenience service within the community and surrounding communities, and finally integrate into a convenience service card distribute to the residents. Residents just dial through the number within convenience service card, there will be staff on-site service. Concrete integration method of related convenience point as shown in Fig. 3.

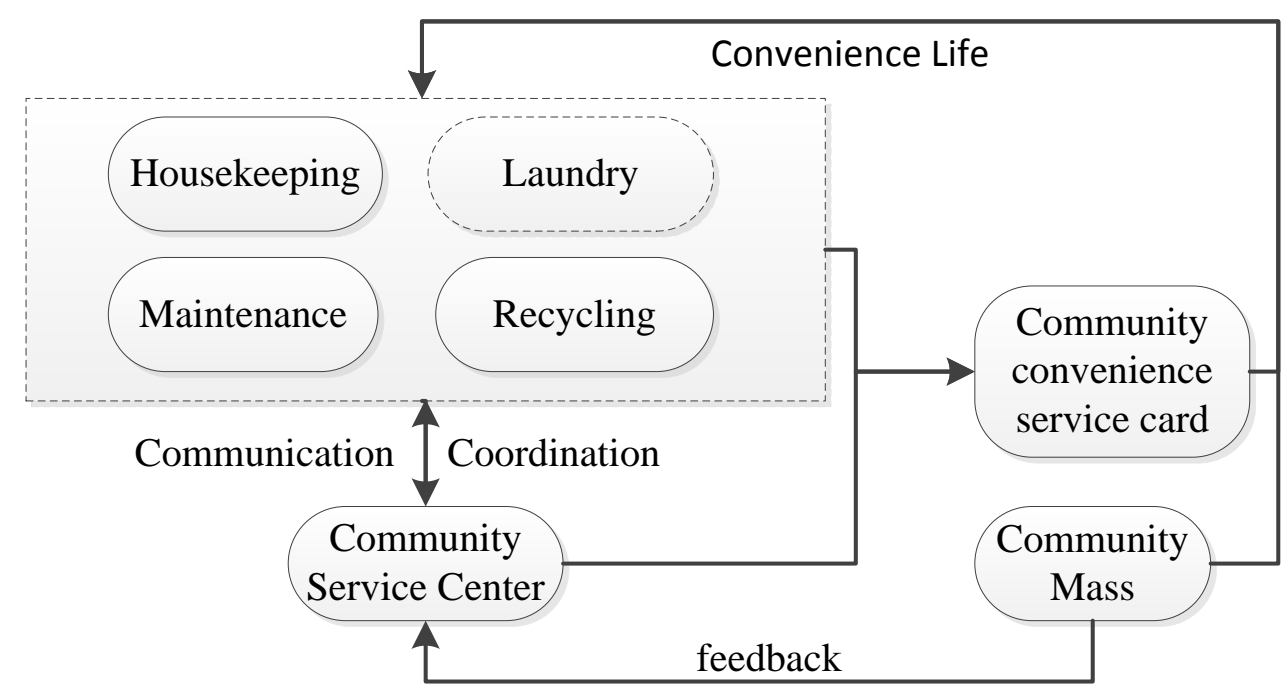

Figure 3. Structure Diagram of Integration of Related Service Resource

3) Functions of Community Convenience Embodiment in Intermediary and Logistics. Take intermediary and logistics company as a small convenient service point, provide free convenience activity such as drinking water, telephone, mobile phone charging, send and receive mail parcels and so on for community residents. Not only convenient the daily life of community residents but also can provide more opportunities to generalization themselves of the related logistics company.

Function of Information Dissemination. Nowadays the attitude of city community residents to participate in the network platform is very positive [8], the network media through contact with the user directly or indirectly to mobilize interactive participation. Function of community information dissemination through LED electronic screen real time brought message to the community residents, such as the policy of the party and country, the related news from the news network 
platform collection, summary and classified. LED electronic screen has advanced multi touch gestures can smooth zoom each page, the convenience of residents reading and reply.

Function of Community Management. Function of community management is based on community information dissemination platform to release some of the latest notice, such as outage notice, water supply shutdown notice, life payment, community promotions, property management and community dynamic change etc. also can explaining to community residents about something happened in community or neighborhood, such as road construction, urban planning.

Function of Life Information. Function of life information can real time obtain the latest local weather information based on existing micro channel platform. Providing the latest traffic congestion in urban areas, remind residents bypass congested roads. Also can inquiry for city traffic routes, the earliest and the latest bus timetable, etc.

\section{Prospection of Community Convenience System}

Construction of community convenience system is not in one day, it needs a long time accumulation, not only in material resources, but also in moral and values. Under such social background, construction of community convenience system must grasp the following principles, the first is the principle of the sustainable development, the strategy of sustainable development in our country has been widely spread, community development also can't be separated from this basic guidelines, the second is the principle of system function, the management of the system will be the focus of our work in the future, the third is the principle of people-oriented, no matter how we development and planning new community convenience system, the final goal is to serve every resident in the community.

At present, during the development of the convenience service system should be on premise of unification thought, insist on humanism at present. We should focus on integrating of community service resources in small range and solving the problems of community service in handle daily life trouble etc. surrounding the requirements of resident's daily life, by understanding the lifestyle and consumption preference of the residents to provide the best service for them.

\section{Conclusion}

With the development and progress of the times, people have different requirements in different historical periods for community convenience services management. In this paper, in order to better construct the community convenience system, we started from the definition of community convenient system and the current situation, Concrete analyze the current status of the community. This paper detailed the functions which the modern community convenience systems should provide in constructing, such as convenient services, information dissemination, community management and life information as well as their implementation practical methods and systematically describe the convenience and benefits which the residents of community can experience from convenience service in their daily life, this paper also discussed the further development of community convenience system in the end, so we are full of confidence.

\section{References}

[1] X. Wu, T.Y. Li. Journal of Urban and Regional Planning: Study on planning and design framework of village and town community convenient service system, Vol. 7 (2015) No.2, p.100-111.

[2] W.Q. Qian. Industrial \& Science Tribune: Construction and Prospect of urban community service system in China, Vol. 14 (2015) No.7, p.5-6.

[3] Norma D.Thomas. Journal of Industrial and Commercial University Of Chongqing: The evolution and future development of the community service system for the elderly in the United States, Vol. 29 (2012) No.3, p.70-76. 
[4] Y. Tan, Z. Yu. Modern Business Trade Industry: Current situation and development of community nursing service system in our country, Vol. 24 (2012) No.13, p.39-40.

[5] F.Q. Li. Journal of Guangdong College of Young Cadres: Review of research on public service of urban community in foreign countries, Vol. 25 (2011) No.3, p.37-42.

[6] J. Zhao. JOurnal of Sinopec Management Institute: Community construction and management of petrochemical enterprises, Vol. 12 (2010) No.2, p.60-66.

[7] L.M. Wang, Y.Y. Wang, T. Lei. Microcomputer \& Its Applications: Design of community service system, Vol. 32 (2013) No.16, p.11-16.

[8] Z.Y. Lan, Y. Liu. Engineering of Surveying and Mapping: Design and implementation of digital community in Guangzhou City, Vol. 21 (2012) No.6, p.38-42.

[9] L.G. Bai. Career Horizon: Function design and typical application of digital community, Vol. 06 (2010) No.7, p.141-143.

[10]L.H. Liu, Y.S. Huang, X.M. Wu. Chinese Medical Equipment Journal: Research and design of remote health service system for community family, Vol. 33 (2012) No.11, p.7-9. 